\title{
Balancing Management Mechanisms for Intermittent Power Sources - A Case Study for Wind Power in Belgium
}

\author{
Kristof De Vos and Johan Driesen
}

\begin{abstract}
To maintain stability within the UCTE-grid, European TSOs are responsible for maintaining a balance between generation, import, consumption and export in their control zones. This responsibility is partly transferred to BRPs which are market participants responsible for the balance between injections and off-takes in their perimeter. With imbalance fees working as incentive to avoid imbalances, BRPs will forecast, schedule and nominate their positions to the TSO before gate closure.
\end{abstract}

With rising interest in electricity from Renewable Energy Sources (RES-e), often characterized by variability, lower predictability and limited controllability, BRPs are facing difficulties meeting their nominated positions in real-time. This gives them a competitive disadvantage. As in most countries RES-e are in fact supported to attain certain penetration levels, system operators and BRPs have to find ways to manage this unpredictability and variability.

Index Terms - wind power, balancing mechanism, wind power integration, intermittent power sources, balancing management

\section{INTRODUCTION}

The European Union has made commitments under environmental, economic and strategic perspective to encourage the penetration of renewable energy sources in European electricity generation. Under Directive 2001/77/CE, the European Commission fixed an indicative objective towards 2010 postulating that $21 \%$ of total electricity consumption in the EU-25 should originate from renewable energy sources [1]. Today, new but binding goals are being set for 2020, which must lead to a share of $20 \%$ renewable energy sources in final European energy demand [2]. However, specific targets for the RES-e share in total electricity consumption are not yet determined.

In 2005, as we can see in Fig. 1, the breakdown of renewable energy sources for electricity production in the EU was dominated by hydropower (66.3\%), followed by wind power (16.3\%) and biomass (15.8\%) [1]. As hydropower is assumed

Manuscript received 15 February, 2009.

K. De Vos is with the research group ELECTA of the department electrical engineering of the K.U.Leuven (ESAT). Kasteelpark 10, 3001 Leuven, Belgium (e-mail: Kristof.DeVos@esat.kuleuven.be)

J. Driesen is with the research group ELECTA of the department electrical engineering of the K.U.Leuven (ESAT). Kasteelpark 10, 3001 Leuven, Belgium (e-mail: Johan.Driesen@esat.kuleuven.be)

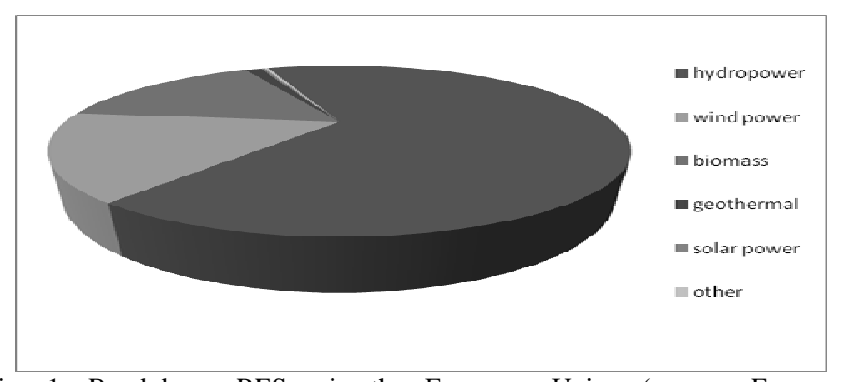

Fig. 1. Breakdown RES-e in the European Union (source: European Commission Energy).

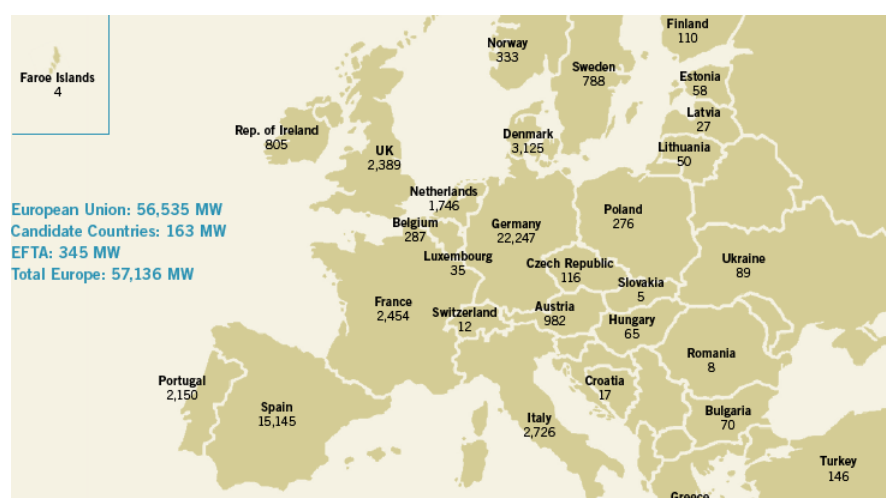

Fig. 2. Wind power cumulatively installed in Europe in 2007 (source: EWEA).

to be limited in capacity due to geographical constraints, wind power is today evaluated as a promising renewable technology for Europe and is being supported to attain RES-e goals [3]. Fig. 2 shows a brief overview of installed wind power capacity in Europe for 2007.

Electricity has however a few characteristics posing constraints to the large-scale penetration of intermittent sources such as wind power. Conditionally to a supply that has to equal demand at each point in time, a limited storability and a variable consumption with a limited predictability, production of electricity requires a certain factor of adaptability, meaning a controllable (possibility of forecasting and adaptability) and flexible output.

However, wind power is flexible but not controllable: it uses a variable energy source which means that output also varies intermittently. This is not a problem for short periods of seconds due to the rotating energy of the large rotor or smoothing effects of wind parks, but will affect the grid if a variation in wind holds on for longer time frames [4]. Wind output is also not fully predictable: a reliable forecast can be made between 5 minutes and 72 hours but standard error will 
increase with longer time horizons [4]. Finally, energy output of wind turbines is dependent on wind speed, resulting in limited control over start-up time and ability to decrease or increase output. However, adaptability improves with time as technology and forecasting models offer new possibilities.

Due to the intermittent characteristics of wind power it can be presumed that higher penetration levels will lead to certain impacts on the grid. More balancing services will be necessary to obtain the same reliability level [5]. These services, procured and activated by the Transmission System Operator (TSO), are accounted to all imbalanced balancing responsible parties (BRPs), resulting in a competitive disadvantage for wind power. In this paper, mechanisms are studied that can be used to balance wind power without harming its competitive position. In a first part, general balancing management mechanisms are discussed which are maintaining grid stability. The second part deals with the specific application of these mechanisms on the production of wind energy in Belgium.

\section{BALANCING MANAGEMENT}

To ensure grid stability, demand and supply have to be kept in balance at all times. Since this has to be realized in realtime, this cannot entirely be left to the invisible hand of the market. Therefore, one task of the TSO is to maintain this balance within its control zone. Balancing management is seen as the management processes and services associated with power system operation, which ensure quality and short term security of supply (ETSO, 2003) [6]. This management consists of different aspects (Fig. 3):

A.the perspective of the TSO: balancing the grid in realtime by contracting balancing services from generators and demand side participants;

B. the perspective of the Balancing Responsible Parties (BRPs): responsible for forecasting, scheduling and balancing their perimeter;

C. the perspective of imbalance settlement, where the local TSO charges imbalance fees to BRPs that are not meeting their balancing responsibility.

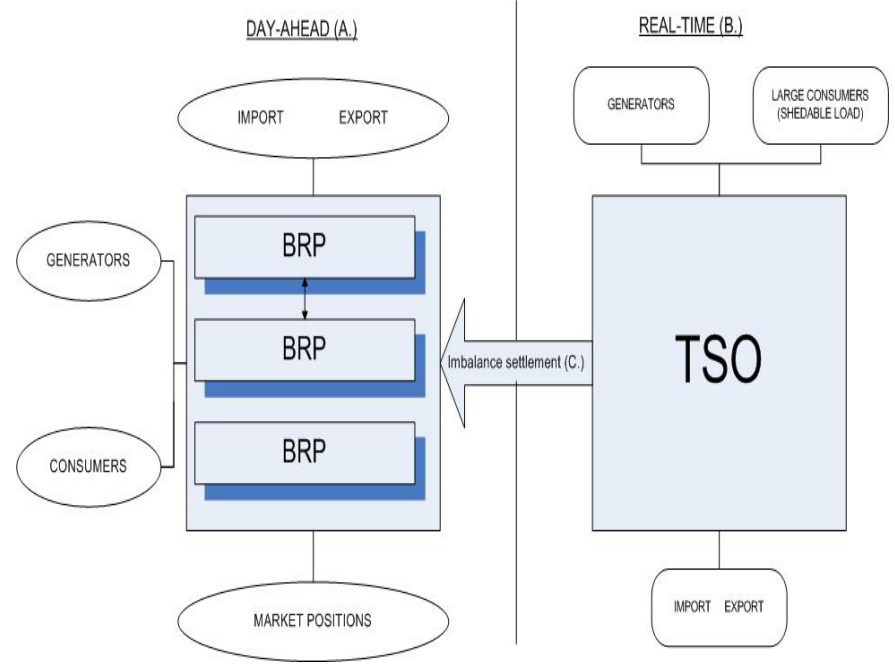

Fig. 3. Schematic overview of the different aspects of balancing management.
Large differences in balancing management exist between European TSOs. The type of interconnection, size, characteristics and types of generating plants in electricity markets have an impact on balance management design. In this chapter a general overview of the different perspectives of balancing management is discussed.

\section{A. Provision of Balancing Services}

The local TSO is the final responsible for maintaining the grid stability and thus the balance between supply and demand in real-time. To fulfill this responsibility, the TSO has the possibility to contract balancing services from generators and/or consumers. In most cases compensated with a certain remuneration, these market participants will lower or higher their production or load. Different services can be grouped in:

- Frequency control services can be divided in primary control and secondary control. The first implies an "automatic reaction of generating sets, involved in primary control, to a frequency deviation caused by a system disturbance or small variations in production and consumption (ETSO, 2003).” These services can therefore only be delivered by power plants having some form of power reserve, usually under the form of (equivalent) inertia. Secondary control, which only exists under this name in the UCTE-zone, is automatically instructed by the TSO and follows the delivery of primary control. Where primary control is a matter of a few seconds, secondary control happens in a range of several minutes. Differences exist between TSOs which concern capacity, frequency drop criteria, time error and technical requirements.

- Reserves and energy balancing services are manually instructed by the TSO and delivered by generators or demand site participants (load shedding). These services vary widely by country.

- Other services affecting balance management include varying reactive power, resolving transmission congestion, accounting for transmission losses and being able to deliver black-start capability.

These services can be procured from generators or consumers by means of bilateral contracts or auctions. Primary control can be obtained commercially or by mandatory obligation (with or without remuneration). Secondary control is generally a commercial service. Reserves and energy balancing services occur by an organized market where generators (or demand participants) can submit bids in order to decrease or increase their output. The TSO accepts these bids in merit order and remunerate these for availability, activation or both with a marginal or bid price.

\section{B. Balancing Responsible Parties (BRPs)}

Each market participant operating in the electricity market is obliged to have a contract with a BRP, or be one. This BRP (aggregating these different market players) is then responsible for keeping the balance between injections and off-takes in its perimeter for each time period meaning:

- physical off-takes in one or more access points; 
- physical injections in one or more access points;

- export/import of electricity to/from neighboring countries;

- transactions with other BRPs.

In Belgium for instance, BRPs are even forced by law (grid code) to deploy at all times all reasonable measures in order to maintain a balance on a quarter-hourly basis.

Generally, BRPs have to submit their physical positions, called nominations, a day in advance to the local TSO. This has to be done before gate closure after which these nominations become fixed and cannot be altered anymore. Before this gate closure (rolling or fixed) BRPs have to predict load and generation, manage their portfolio and take positions in the market. After gate closure, the TSO will check all nominations for consistency and congestion problems and officially approves, declines or suggests certain adaptation to the nominations in order to maintain overall grid stability.

In case of unforeseen events after gate closure leading to a real-time imbalance between injections and off-takes, the BRP can often correct its position by managing its own portfolio (adaptable generation or load) or by using certain balancing tools (if existing) installed by the local TSO (intraday trading, imbalance pooling) which are further explained in section 3.

In real-time, the TSO as final responsible party, balances the grid using contracted balancing services. The TSO corrects the real-time imbalances of BRPs and manages the balance within the time period where BRPs are not responsible for. For instance, BRPs deviations in Belgium within the 15 minutes time period are not penalized if mean imbalance over this period remains zero. If this is not the case, meaning that the metered energy volumes in real-time do not match the nominated volumes for the specific time period (the cumulative power flow in 15 minutes), the TSO will clear this imbalance by means of his contracted control services and charge the responsible BRPs an imbalance fee for the use of this service.

\section{Imbalance Settlement}

The TSO is responsible for the final grid balance and acts as buyer of balancing services for a specific control area. The TSO procures the different categories of control services from inside or outside its control zone in order to maintain the balance.

When a BRP is not in balance, meaning it is short (injections $<$ off-take) or long (injections $>$ off-take), it will in most countries be charged with an imbalance tariff for the balancing service delivered by the TSO. There are different systems to calculate this fee: dual/single imbalance pricing, average/marginal pricing, split production/consumption account or not [7]. However with this fee, TSOs discourage market parties in their control area to rely on these balancing services and transfer balancing responsibility as much as possible to different BRPs in the control area [8]. The imbalance price has to motivate BRPs on the short term to monitor and manage their portfolio and market positions to use every means to avoid an imbalance. On the long term this fee should foster investments in, or contracts with, flexible production capacity.

\section{BALANCING WIND ENERGY IN BELGIUM}

As explained in the introduction, wind power is characterized by a certain variability and a limited predictability which implies challenges in balancing management, leading to a competitive disadvantage for BRPs with wind generation in their portfolio. Though, when wind power is chosen as today's best alternative to boost RES-e in Europe, mechanisms have to be deployed to deal with this variable and not entirely predictable output.

\section{A. Wind Power Supporting}

To promote the integration of RES-e in Belgium, a system of green certificates together with a priority dispatch has been opted for [9]. This ensures maximal renewable output, but also increases the pressure on balancing services. In certain cases, the Belgian TSO has however the possibility to curtail off-shore wind power in order to guarantee the stability of the grid. Up to $60 \%$ (in winter period) of wind output in can be curtailed by the Belgian TSO (Elia) without giving a compensation. When more has to be curtailed, producers are compensated for their lost green certificates [10].

Another common used support scheme is the use of feed-in tariffs alongside a priority dispatch, such as for instance in France and Germany. Similar to Belgium, German TSOs can curtail wind power production in case of grid congestion with $100 \%$ electricity from RES [11]. This curtailment means a lost income for the wind park operators and thus an extra investment risk but it has been decided that these losses will be compensated as from 2009.

The Netherlands are one of the few countries in Europe that treats wind energy the same way as other electricity producing technologies. Wind power is in contrast to Germany or Belgium not prioritized and feed-in tariffs were set to zero from August 2006 [12].

\section{B. Responsabilization}

In Belgium, BRPs with off-shore wind generation in their portfolio (accepted as from 2009) will not be entirely responsible for imbalances due to off-shore production (Fig. 4). Off-shore wind farms receive a tolerance margin of $30 \%$ (in contrast to the $10 \%$ margin for on-shore wind power). Only imbalances exceeding this margin are subordinated to the fees enforced by the local TSO. Imbalances that stay within the margins will be purchased or sold by Elia at $90 / 110 \%$ of the price quoted on the Belpex day-ahead market (Belgian Power Exchange, founded in 2005 and coupled with French and Dutch power exchanges). Off-shore production forecasts have to be nominated day-ahead before $10 \mathrm{~h} 30$ after which the tolerance band is determined. For instance, if a producer nominates $200 \mathrm{MW}$ offshore production from $00 \mathrm{~h} 00$ till $12 \mathrm{~h} 00$ and $100 \mathrm{MW}$ for the rest of the day, this band is respectively $140 / 260$ until $12 \mathrm{~h} 00$ and $70 / 130$ after. This nomination can be adapted intra-day which also changes the margin band [10]. Discussion exists however why off-shore wind should receive such larger advantage whereas no higher 
variability or unpredictability - often on the contrary - is expected compared to on-shore.

In Germany, generation facilities falling under the feed-in scheme are exempted from all balancing responsibilities, which means that they do not have to submit generation schedules or pay imbalance fees to the TSO. Forecasting, scheduling and balancing are done by the TSO which results in central forecasting with more accurate results due to geographical dispersion of variability. However, balancing costs are accounted to the end-consumer which means that TSOs in Germany do not have a market-driven motivation to improve forecasting or imbalances.

BRPs in the Netherlands are, in contrast to Germany, fully responsible for balancing of intermittent wind power in their portfolio.

\section{Day-Ahead Nomination}

In Belgium, every market participant has to be connected to a BRP that balances its positions for every 15 minutes for all its access points (aggregated) and minimizes deviations between these nominated positions and real-time. Nominations have to be sent to Elia before a fixed gate closure. This includes expected injections and off-takes at access points, nominations for power exchanges between BRPs and import and export nominations at the border of the control area [13].

As can be seen in Fig. 5, gate closure is at $14 \mathrm{~h} 00$ which means that BRPs have to schedule their production and loads between 10 and 34 hours in advance. The day-ahead market closes even at $11 \mathrm{~h} 00$ which adds three more hours to this forecasting horizon if market players want to use Belpex. This can be difficult for wind generators where output is variable over time, not entirely predictable and forecasting errors increase with time horizon. This problem also counts for the Netherlands were gate closure is also at $14 \mathrm{~h} 00$ and the APX day-ahead market closes at $11 \mathrm{~h} 00$.

The French system is however somewhat different, BRPs have to send a Call and Forecast Program to the French TSO (RTE) with called and forecasted generation for each 30 minutes of the next day. System access deadline (gate closure) for this is $16 \mathrm{~h} 00$ at which also a declaration of performances and technical constraints has to be sent for each generation group in the BRPs' portfolio. RTE is in that way provided with the scheduled power flows and excess capacity needed for his final balancing responsibility. In a second phase, BRPs can alter their call program for every period, as well as the declaration of technical constraints and performances, after system access deadline and before one of the 24 intra-day gate closures positioned on the hour where the first is positioned at 22h00 D-1 [14]. This rolling gate closure offers BRPs in France more freedom and is thus positive for the integration of wind power. However, the day-ahead market (Powernext) closes at $11 \mathrm{~h} 00$ which means that BRPs have to take positions between 11 and 36 hours before real-time but they can adjust their portfolio in other ways till gate closure at $16 \mathrm{~h} 00$ (or even later using the complementary gate closures at which redeclaration can be submitted).

\section{Intra-day Balancing Mechanisms}

Different mechanisms can be applied in Belgium by a BRP to avoid an imbalance after gate closure.

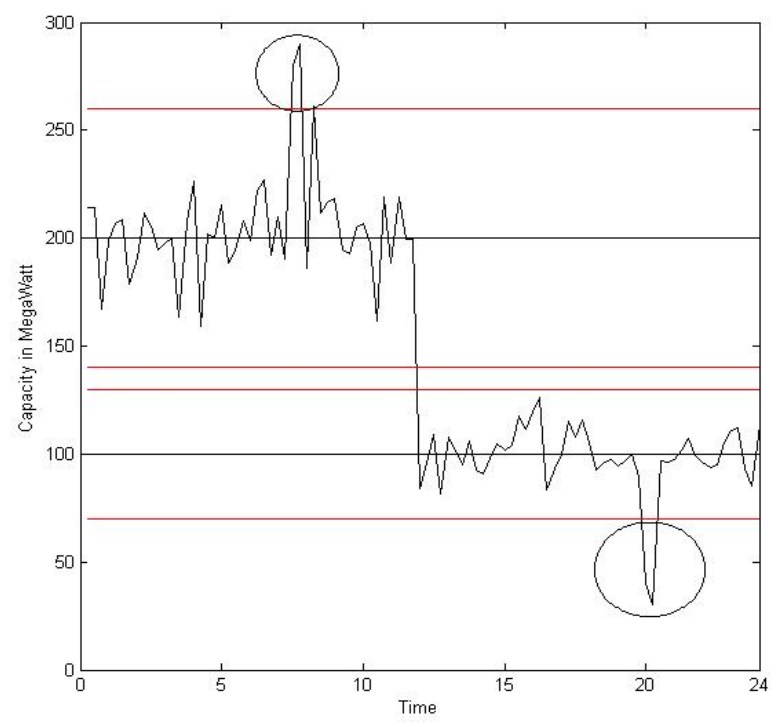

Fig. 4. Example of the Belgian 30\% tolerance margin where a BRP nominates 200 MW off-shore production for the first part of an arbitrary day and 100 MW for the second.

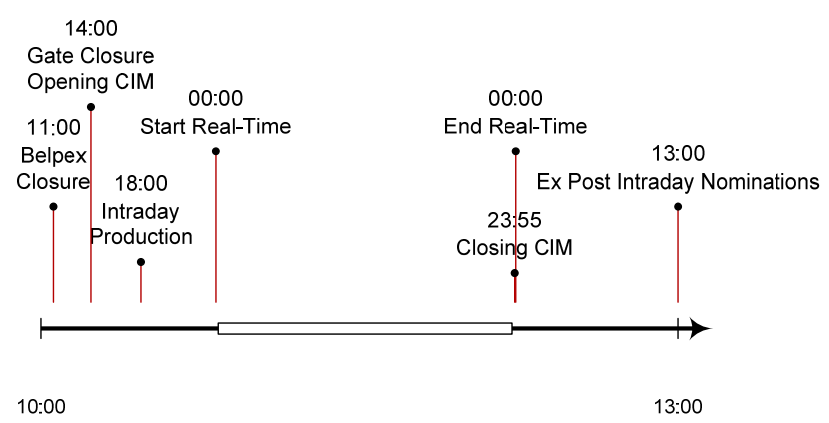

Fig. 5. Chronological representation of balancing activities in Belgium for an arbitrary day.

\section{- Portfolio Management}

As a first alternative, BRPs can manage their portfolio to intercept expected imbalances. To achieve this, they can use reserve power from flexible generation or customers to compensate for example in case of lower/higher wind speeds. This is not always possible for smaller BRPs with limited production capacity. As in Belgium most BRPs are relatively small in comparison to the incumbent, they face a competitive disadvantage concerning balancing possibilities. Additionally, balancing capacity needs to be flexible such as for instance certain hydropower or CCGT plants. However, the first is not extensively available in Belgium and the second is rather expensive. Today, wind turbines themselves can also be used to manage the portfolio balance by new control technologies or the aggregation of geographically dispersed wind parks (which will not be applicable in a small country as Belgium).

A second alternative falling under portfolio management is hedging by taking positions in the market. A BRP can contract for instance production or load and tune its portfolio to this. 
When it buys for instance generation and there is no wind it can absorb this imbalance with its position on the spot market. When there is enough wind, the BRP can reduce output of his most expensive generators. As the Belpex day-ahead market closes 13 to 37 hours before real-time, possibilities are in fact limited.

\section{- Intra-day Transactions}

Next to portfolio management, BRPs can also maintain their balance after gate closure with intra-day transactions. It is for instance possible to execute bilateral exchanges with other BRPs after gate closure (starting after Day-ahead HUB Confirmation). The nomination itself has to be send to Elia before $01 \mathrm{~h} 00$ the next day [16].

To facilitate this market, an intra-day market on the power exchange Belpex has been opened (13 march 2008) where market participants are able to find positions or counterparties to trade after gate closure (from 14h00 and to 5 min before real time) and this for 24 blocks of one hour, or blocks of 4 or 6 hours. However, this market still suffers low liquidity which should improve with market coupling and when more generation capacity becomes available.

In 2009, Elia is starting with an Intra-day Production Mechanism which gives BRPs the possibility to adapt their nominations intra-day. This request can be submitted as from $18 \mathrm{~h} 00 \mathrm{D}-1$ (also the time at which Elia approves or adapts day-ahead nominations according to congestion management measures) and at least 1 hour before real-time. For instance, to adapt nomination for $22 \mathrm{~h} 00$, this request has to be send before 21h00. However, Elia retains the right to decline or approve but after acceptance, it cannot withdraw this right anymore without remuneration.

Also import and export with respect to the defined timing is allowed on the France-Belgium interconnection (Intra-day Allocation Mechanism) (Table. 1)[17]. At 12 moments after gate closure the participant can nominate an import or export within the limit of the allocated capacity, between France and Belgium at the given gate. Each gate takes place in different stages. This means for the first gate that the TSO publishes available capacity after which participants submit their request for capacity before allocation gate closure $(21 \mathrm{~h} 00)$. This is allocated by the TSO before $21 \mathrm{~h} 30$. Then, participants can submit nominations before $22 \mathrm{~h} 00$ that have to be confirmed before $22 \mathrm{~h} 45$. Finally, the delivery period takes place between $0 \mathrm{~h} 00$ and $24 \mathrm{~h} 00$ and repeats itself 12 times.

\section{- Imbalance Pooling}

Complementary to previous mechanisms, BRPs can also pool their imbalances with other BRPs by signing a "Pooling Agreement". This means that Elia will invoice the global netted imbalance to one of the BRPs in the pool [13]. This BRP divides this total cost among the participants of the pool according to their individual imbalance. This technique should reduce the total imbalance volume due to counterbalancing of opposite imbalances of different BRPs.

In practice, this technique is not often used. This can be explained by a confidentiality threshold in sharing imbalance information. Additionally, this tool is also not optimal in a situation where one player is much larger than others. Imbalances of this player are difficult to neutralize, leading to disproportional benefits.

\begin{tabular}{|c|c|c|c|c|}
\hline Gate & $\begin{array}{c}\text { Time limit for } \\
\text { sending Intra- } \\
\text { day Access } \\
\text { Authorizations }\end{array}$ & $\begin{array}{c}\text { Time limit for } \\
\text { receiving } \\
\text { Nominations }\end{array}$ & $\begin{array}{c}\text { Time limit for } \\
\text { Nomination } \\
\text { confirmations }\end{array}$ & Delivery period \\
\hline $21 \mathrm{H} 00 \mathrm{D}-1$ & $21 \mathrm{H} 30$ & $22 \mathrm{H} 00$ & $22 \mathrm{H} 45$ & $00 \mathrm{H} 00-24 \mathrm{H} 00$ \\
\hline$T$ & $\mathrm{~T}+30 \mathrm{~min}$. & $\mathrm{T}+1 \mathrm{~h}$. & $\mathrm{T}+1 \mathrm{~h} .45 \mathrm{~min}$. & $(\mathrm{T}+2 \mathrm{~h})-.24 \mathrm{H} 00$ \\
\hline
\end{tabular}

Table 1. Intra-day Allocation Mechanism for the French-Belgian border (source: Elia).

\section{- Reserve Market Bids}

Another possibility is to sell reserves to Elia through the intra-day market. Under article 159, paragraph 2, of the technical code (Royal Decree 19.12.2002), producers with a capacity more than 75 MW are obligated to keep their available capacity at the disposal of Elia at a price they fix when they submit nominations (14h00). These are then activated by Elia in merit order. With the intra-day production it becomes possible to adapt these prices intra-day (18h00) [10].

\section{DeVElopment OF INTRA-DAY MARKET}

Before the development of intra-day markets, the main problems for BRPs trying to avoid imbalances were timing of gate closure and day-ahead market closure. The latter reduces possibilities to find trading counterparties in the market and the first stops all possible adaptations of positions taken, giving wind production a disadvantage because output predictability improves with shorter time horizons.

This problem has been addressed by the development of different tools such as intra-day gate closures (France) or imbalance pooling agreements. Maybe the most important evolution has been the development of intra-day trading possibilities. This market tool permits the BRP to find counterparties (bilateral contracts) after gate closure to buy or sell electricity in order to rebalance its nomination after gate closure if predictions adapt themselves to new information (this possibility is in fact an alternative for a postponed gate closure which has been heavily defended by wind producers).

To improve market transparency and liquidity, intra-day markets were opened in different countries where BRPs could find anonymous counterparties for trading, following the example of day-ahead markets. However liquidity on these new markets seems to be a problem. This can often be explained by the shortage of flexible production capacity in the countries concerned. To attain a good integration, wind power has to be combined with flexible power plants. CCGTplants or pumped hydro are suitable but usually have quite high operational costs. Large hydro plants are cheaper but their capacity is limited to geographical conditions. Such flexible generators are however indispensable for real-time balancing or balancing by BRPs after gate closure. A second important condition is geographical dispersion (especially in 
scenarios with increasing wind power). However, not all countries, like for instance Belgium or the Netherlands, have the capacity to achieve this [18]. The availability of flexible production capacity is however important for BRPs balancing their portfolio, where counterparties have to be found possible and willing to sell flexible generation capacity or trading opposite imbalances.

Therefore, international coupling of intra-day markets can improve liquidity as more market players become available. Availability of flexible capacity, as seen in previous paragraph, depends on national geographic conditions. This means that some countries could attain a higher share of wind penetration, but when international markets are introduced and further developed, the overall liquidity of these markets will also improve. With the new connection between Norway and The Netherlands as an example, cheap hydropower becomes available to balance Dutch wind generation. As seen in this text, such intra-day capacity exists on the French-Belgian border but is however limited in capacity. Further investments in cross-border capacity and market coupling can also play an important role in the development of intra-day markets and wind power.

In France, with a larger amount of flexible hydro power and dispersed wind generation, we would expect liquid balancing markets. However, in practice this seems not true at all due to certain market barriers. France is, like most countries due to historical market architecture (for instance Belgium), characterized by a dominant player with certain market power (by holding high percentages of national production capacity) [19]. This player can have incentives to keep its bids in the balancing market scarce. For instance, to stimulate trade in the forward market, pushing these prices, or simply for competitive reasons (supply competitors with cheap balancing power). This market power can prevent small players balancing their positions after gate closure. Portfolio management is after all not always possible for little BRPs with small capacity.

\section{CONCLUSION}

Due to the variable and limited predictability of wind power, BRPs managing wind power in their portfolio are coping with an extra uncertainty, namely the output of their wind production sites. This has an important impact on wind power production because deviations between nominated and real-time power production give rise to imbalance costs.

Wind power output can be managed on different markets. A common way to operate in environments characterized by uncertainty is hedging which is frequently applied by BRPs to remove uncertainty in wind power sales. They use a wind and price index to sell their expected output via long term contracts on the over the counter (OTC)-market. With financial hedging instruments, risk can be removed at a certain cost on a yearly, quarterly, monthly or weekly basis for baseload output. When day-ahead arrives and wind power becomes relatively well predictable, surpluses or deficits can be traded on the day-ahead. However, predictability will now play an important role, because market positions and nominations sent to the TSO are based on forecasted wind production.

After day-ahead gate closure, imbalances in Belgium can today be traded in an intra-day market. However, this market still suffers from illiquidity. To attain a good working liquid intra-day market it is important to create a competitive environment, which means flexible generation capacity should be extensively available without monopoly power. Additionally, access to international markets is likely to improve competition and access to flexible generation. When liquidity on intra-day markets improves, these markets can form an alternative to a postponed gate closure promoted by wind power industry.

\section{REFERENCES}

[1] European Commission Energy, Renewable Energy Road map, http://europa.eu/scadplus/leg/en/lvb/l27065.htm, consulted January 2009

[2] European Commission Energy, Renewable Energies, http://ec.europa.eu/energy/renewables/index_en.htm,consulted January 2009

[3] EWEA, "Pure power : wind energy scenarios up to 2030", March 2008, www.ewea.org

[4] Thiroux, C. (2007) "l'Insertion d'une production inflexible dans des marches concurrentiels : l'energie eoliénne", pp. 21-30, Doctoral Thesis, Université de Paris

[5] Wind Energy, The Facts, http://www.wind-energy-the-facts-org, consulted January 2009

[6] ETSO, "Current State of Balancing Management in Europe”, December 2003, www.etso.be

[7] Vandezende, L., Meeuws, L., Belmans, R., Saguan, M., Glachant, J. (2009) "Well-functioning balancing markets as a prerequisite for wind power integration" Energy Policy, forthcoming

[8] Vandezande, L., Meeus, L., Belmans, R. (2008) "The next step in the Central Western European electricity market: cross-border balancing.” Revue E tijdschrift, 1-2008 (124), pp.19-24

[9] Souto Perez, P., Van Hertem, D., Driesen, J. , Belmans, R. (2006) "Wind power in the European Union, grid connections and regulatory issues" IEEE PES Power Systems Conference \& Exposition , Atlanta, Georgia, USA, Oct.29-Nov.1, 2006; pp. 776-783

[10] Vandenbroucke, H. , Market Mechanisms \& Tariffs, Elia, personal communication, January 2009

[11] Klessman, C., Nabe C., Burges, K. (2008) "Pros and cons of exposing renewable to electricity market risks: a comparison of the market integration approaches in Germany, Spain and the UK." Energy Policy, Elsevier, vol. 36(10), pp. 3646-3661, October

[12] Kling W., Ummels, B., Hendriks, R. (2007) "Transmission and system integrations of wind power in the Netherlands", Power Engineering Society General Meeting, 2007, IEEE, 24-28, June 2007, pp. 1 - 6

[13] Elia, "ARP Contract, practical Modalities of the Balance obligation", version 2.0; 10/05/2007, www.elia.com

[14] RTE, "Rules relative to Programming, the Balancing Mechanism, and the Balance Responsible Entity System" version applicable as of $3^{\text {rd }}$ September 2007, www.rte.be

[15] Ummels, B., Gibescu, M., Kling, W., Paap, G. (2006) "Integration of wind power in the liberalized Dutch electricity market” Wind Energy. 2006; 9; pp. 579-590

[16] "Intra-day Internal Energy Transfer: Intra-day HUB, procedure" version 1.1; 20/12/2006, www.elia.be

[17] Elia, "Allocation on the France-Belgium interconnection: Intra-day allocation mechanism, information note" 27/03/2008, www.elia.be

[18] Soens, J. (2005), "Impact of wind energy in a future power grid" Doctoral Thesis, K.U.Leuven

[19] Battle C., Vázquez, C. and Barquín J. (2007) "The balancing market maker: a tool to enhance liquidity in the French Balancing Mechanism" The Electricity Journal, 20 (6), pp.76-86, July 2007 